\title{
Drug-Induced Nephrotoxicity in Inflammatory Bowel Disease
}

\author{
Konstantinos A. Oikonomou ${ }^{a}$ Andreas N. Kapsoritakis ${ }^{a}$ Ioannis Stefanidis ${ }^{b}$ \\ Spyros P. Potamianos ${ }^{\text {a }}$ \\ Departments of a Gastroenterology and ${ }^{\mathrm{b}}$ Nephrology, University of Thessaly, School of Medicine, Larissa, Greece
}

\section{Key Words}

Inflammatory bowel disease $\cdot$ Nephrotoxicity .

Tubulointerstitial nephritis - Glomerulonephritis ·

Aminosalicylates $\cdot$ Cyclosporine $\cdot$ Tumor necrosis factor- $\alpha$ inhibitors

\begin{abstract}
Conservative management of inflammatory bowel disease (IBD) is based on a combination of drugs, including aminosalicylates (ASAs), steroids, antibiotics, immunosuppressives and biologic agents. Although various side effects have been related to treatment regimens, drug-induced nephrotoxicity is rather uncommon. Furthermore, it is often underestimated since renal function deterioration may be attributed to the underlying disease. The nephrotoxicity of ASAs and cyclosporine A seems well established, but recent data have suggested a possible role of biologic agents such as infliximab and adalimubab in renal impairment. The aim of this review is to summarize the nephrotoxic effects of medical treatment as well as to express possible caveats in the administration of novel agents in IBD.
\end{abstract}

Copyright $\odot 2011$ S. Karger AG, Basel

\section{Introduction}

Ulcerative colitis (UC) and Crohn's disease (CD) represent the two major forms of inflammatory bowel disease (IBD), affecting approximately 3.6 million people in the USA and Europe [1]. IBD is often accompanied by several extraintestinal manifestations, occurring in $6-47 \%$ of IBD patients. Regarding renal and urinary involvement in particular, an incidence of $4-23 \%$ has been demonstrated. Nephrolithiasis, amyloidosis, tubulointerstitial nephritis (TIBN) and glomerulonephritis (GN) are considered as established manifestations, significantly correlated with bowel inflammation [2]. However, even when the above-mentioned entities are absent, microalbuminuria, as a sign of minimal renal dysfunction, may be present, reflecting disease activity [3].

Nevertheless, inflammation itself does not appear to be the only factor impacting renal function in IBD. Druginduced nephrotoxicity is a rare but significant complication in IBD patients [4]. In order to evaluate the potential nephrotoxic drugs in IBD, pharmaceutical agents utilized to treat active disease and maintain remission should be mentioned [5]. Corticosteroids such as prednizolone and budesonide and antibiotics such as ciprofloxacin and metronidazole are considered as first-line therapy to induce remission in both UC and CD. Aminosalicylates (ASAs), including sulfasalazine and mesalazine, are associated with clinical improvement in active UC and are essential in maintaining remission; however, the efficacy of mesalazine is debatable in CD and seems to be beneficial only in mild ileocolonic disease. As secondline therapy, in order to achieve and maintain remission, thiopurines (azathioprine and 6-mercaptopurine) are effective in both UC and CD, whereas cyclosporine has a role in refractory UC and methotrexate in inducing re-

\section{KARGER}

Fax +41 613061234 E-Mail karger@karger.ch www.karger.com

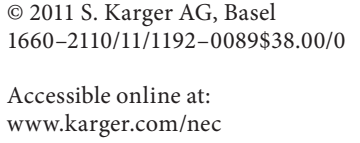

Konstantinos A. Oikonomou, MD

Mezourlo

GR-41110 Larissa (Greece)

Tel. +30 2410234427

E-Mail acoseko@yahoo.com 
Table 1. Potential nephrotoxic effects of medical treatment in patients with IBD

\begin{tabular}{|c|c|}
\hline Agents & Main nephrotoxic effects \\
\hline 5-ASAs & TIBN, GN \\
\hline CsA, tacrolimus & $\begin{array}{l}\text { renal vasoconstriction, } \\
\text { interstitial fibrosis }\end{array}$ \\
\hline $\begin{array}{l}\text { TNF- } \alpha \text { inhibitors } \\
\text { (infliximab, adalimubab) }\end{array}$ & GN \\
\hline $\begin{array}{l}\text { Thiopurines (azathioprine, } \\
\text { 6-mercaptopurine) }\end{array}$ & $\begin{array}{l}\text { none, primary-collapsing } \\
\text { glomerulopathy, acute } \\
\text { kidney injury and severe } \\
\text { nephrotic syndrome due to } \\
\text { hematophagocytic syndrome }\end{array}$ \\
\hline Corticosteroids & none \\
\hline Methotrexate & none at conventional doses \\
\hline Mycophenolate mofetil & none \\
\hline $\begin{array}{l}\text { Antibiotics (mainly cipro- } \\
\text { floxacin and metronidazole) }\end{array}$ & $\begin{array}{l}\text { extremely rare events of } \\
\text { TIBN related to ciprofloxacin }\end{array}$ \\
\hline $\begin{array}{l}\text { Total parenteral or enteral } \\
\text { nutrition }\end{array}$ & none \\
\hline
\end{tabular}

mission and preventing relapse in CD [6]. Tumor necrosis factor- $\alpha$ (TNF $\alpha)$ inhibitors, such as infliximab and adalimubab, are efficacious in $\mathrm{CD}$, while infliximab shows efficacy in UC, as well [7]. Among the aforementioned agents, ASAs, cyclosporine and TNF $\alpha$ inhibitors have been previously reported to affect the kidneys and provoke mild or severe renal impairment via different pathophysiological pathways [2]. Given the extensive utilization of these drugs, we attempted to highlight the impact of medical treatment on renal function of IBD patients. Table 1 summarizes potential nephrotoxic effects of pharmaceutical treament administered to IBD patients.

\section{Aminosalicylates}

5-ASAs are the main therapeutic approach in IBD patients. Free 5-ASAs are unstable in acid and largely absorbed in the proximal intestine. Therefore, different formulations have been developed to induce 5-ASA absorption from the inflamed intestinal tissue. Both the combined form of sulfasalazine (5-ASA bound to sulfapyridine) and the coated form of 5-ASA (mesalazine, olsalazine) have been reported to be responsible for renal toxicity [8]. The established efficacy of 5-ASAs in inducing and maintaining clinical remission in IBD led to a great number of trials concerning possible renal adverse events, which concluded that renal function may be directly affected by 5 -ASA administration. Renal impairment may occur in up to 1 in 100 patients treated with 5-ASA, but clinically significant damage would occur in only 1 in 500 patients $[3,9]$.

Renal toxicity due to 5-ASA may present as GN, minimal-change nephropathy with nephrotic syndrome and interstitial nephritis, which may be associated with nephrogenic diabetes insipidus [10-17]. In many cases, it remains unclear whether renal impairment emerges as an extraintestinal manifestation or as an adverse drug effect. However, it is supported that 5-ASA may be causal in initiation of interstitial nephritis of patients with IBD. The subsequent reversal of this renal impairment, albeit partial, was temporally related to drug withdrawal $[9,18,19]$.

A few cases of renal toxicity have been reported with sulfasalazine in the form of an idiosyncratic, dose-independent phenomenon occurring as a part of a generalized hypersensitivity reaction [20]. Mesalazine, on the other hand, has been reported to be responsible for a significant number of patients developing nephritis during its administration [21]. Mesalazine may provoke acute or chronic interstitial nephritis $[13,19,22]$. Patients with mesalazine nephrotoxicity show a striking male predominance [9]. Several clinical trials have reached the conclusion that TIBN in IBD patients during mesalazine treatment is not related to dosage or time of exposure, suggesting that cumulative exposure is not a significant factor for TIBN development $[3,8,23]$ although a recent report by Patel et al. [24] suggests that a significant dose- and treatment duration-dependent decline of creatinine clearance is present in IBD patients. Symptoms such as malaise, fever, eosinophilia, skin rash may emerge as signs of TIBN, the absence of which, however, does not exclude 5-ASA nephrotoxicity. Renal biopsy can determine whether interstitial nephritis is the cause of renal deterioration [9].

The exact mechanism of induction of TIBN and the site of initiation within the kidney are not known. Only a minority of patients manifest a systemic type-1 hypersensitivity with fever and eosinophilia. Mesalazine is structurally related to salicylic acid and phenacetin, both of which are associated with the entity of 'analgesic nephropathy', which is characterized by interstitial nephritis and papillary necrosis. In the kidney, salicylate is both filtered and actively secreted by proximal tubules via the basolateral organic anion transporter. Passive reabsorption occurs throughout the nephron resulting in high cortical and medullary concentrations. Salicylates, inhibit the synthesis of intrarenal prostaglandins, which 
are vasoactive mediators of intrarenal blood flow and uncouple oxidative phosphorylation in mitochondria. These effects, either alone or in combination with other events, cause a regional disturbance of intrarenal blood flow and local tissue hypoxia. High intrarenal concentrations of salicylate also inhibit the pentose phosphate shunt, reducing renal glutathione and rendering the kidney susceptible to oxidative damage. Ischemic reperfusion injury induces an inflammatory response at the endothelial level, causing inflammatory cell recruitment to local tissue. Tissue injury from recurrent hypoxia/reoxygenation, possibly related to peak plasma interstitial levels of salicylate exacerbated by reduced renal glutathione, could contribute to chronic inflammation and interstitial fibrosis. Direct tubular toxicity in addition to tissue hypoxia is also suggested [21].

The development of TIBN, either as an idiosyncratic response or as a nephrotoxic effect, suggests prompt discontinuation of 5-ASA therapy. The injury is usually reversible, but when diagnosis is delayed, it may be permanent $[9,13,15]$. Steroid or immunosuppressive therapy may improve renal dysfunction $[9,13,14]$.

Although the mechanisms of 5-ASA nephrotoxicity have been analytically demonstrated, suggesting that renal function deterioration due to 5-ASAs is possible, a number of recent reports have shown IBD activity as the main factor responsible for renal impairment. Tubular proteinuria such as microalbuminuria has been demonstrated to be present in the majority of IBD patients, and seems to be related to disease activity rather than to 5-ASA treatment [25-32]. Even if users of 5-ASAs have an increased risk of renal disease, this risk may be partially attributable to the underlying disease. Furthermore, the incidence appears to be low and does not appear to be related to either the dose or type of 5-ASA used [25]. Regarding assessment of the renal function of IBD patients treated with 5-ASAs, it has been suggested that it should be monitored every 4 weeks during the first 3 months of 5-ASA therapy to identify patients who may be at risk of developing progressive renal damage. Monitoring can be reduced to 3-monthly for the first year and to yearly for the next years. Increased monitoring frequency is warranted in patients receiving steroid therapy since this may camouflage symptoms of significant renal damage during 5-ASA treatment $[3,9]$. However, the optimal monitoring schedule in patients receiving 5-ASA treatment remains to be established as there is no evidence to date that either the test, or the frequency of testing, improves patient outcomes [3].

Nephrotoxic Drugs in IBD

\section{Cyclosporine}

Cyclosporine A (CsA) is a neutral lipophilic cyclid peptide which interrupts the cellular immune response by inhibiting calcineurin and thus blocking mainly the production of interleukin- 2 and interferon- $\gamma$ by T-helper lymphocytes. It has been proposed as a rapid-acting alternative or adjunct to azathioprine or 6-mercaptopurine therapy in IBD [33]. Numerous trials attempted to clarify its efficacy in CD and UC, using as guide the proven efficacy of CsA in other immune-related diseases such as psoriasis and rheumatoid arthritis [34]. The results of these trials led to the suggestion that CsA is effective only in refractory fulminant UC [35-37] and severely active CD [34, 38-42].

Two approaches of CsA administration have been investigated; low-dose CsA (oral dose of $\leq 5 \mathrm{mg} / \mathrm{kg} /$ day) and high-dose CsA (oral dose of $>5 \mathrm{mg} / \mathrm{kg} /$ day or intravenous dose of $4 \mathrm{mg} / \mathrm{kg} / \mathrm{day}$ ), which exhibited dose-related nephrotoxicity $[43,44]$. Administration of low-dose CsA exhibited no serious nephrotoxicity [41], whereas side effects from high-dose CsA provoked renal impairment in $6 \%$ of patients $[39,43]$. In all, patients undergoing CsA treatment for autoimmune diseases, including IBD, will have a $20 \%$ reduction in their glomerular filtration rate [45].

CsA can cause acute renal dysfunction by producing intense afferent arteriolar vasoconstriction, resulting in decreased renal blood flow and glomerular filtration rate and increases in serum creatinine [45]. Reduction or discontinuation of CsA usually improves renal function after 5-7 days [46]. There are many factors mediating CsAinduced vasoconstriction such as endothelin, thromboxane $A_{2}$, nitric oxide synthase inhibition and activation of the sympathetic nervous system, and their regulation demands appropriate pharmacologic maneuvers [45, 46].

Furthermore, CsA may provoke chronic renal impairment. It has been reported that histological evidence of nephropathy occurred in $21 \%$ of patients treated with oral CsA for autoimmune diseases revealing that manifested as striped interstitial fibrosis and tubular nephropathy in $15 \%$; moderate to severe arteriolar alterations in $2 \%$; or both in 5\% [19]. The exact mechanism of chronic CsA nephrotoxicity remains unclear, although intrarenal activation of the renin-angiotensin system has been suggested to play a significant role [47].

Considering its nephrotoxicity in IBD patients, it has been suggested that CsA should be administrated in doses $<5 \mathrm{mg} / \mathrm{kg} /$ day [43]. However, a number of controlled trials in CD did not show a beneficial treatment effect

Nephron Clin Pract 2011;119:c89-c96 
when low-dose CsA was administered. On the other hand, a few uncontrolled trials have suggested efficacy of high-dose CsA in active CD. In UC, although better results were shown with low-dose CsA, as well as greater efficacy at high doses, only $50 \%$ of patients will finally avoid colectomy. Given the higher rates of nephrotoxicity of high-dose CsA and its efficacy, previous reports conclude that short-term CsA administration (oral doses of $>5 \mathrm{mg} / \mathrm{kg} /$ day or intravenous doses of $4 \mathrm{mg} / \mathrm{kg} /$ day) is advisable only in refractory UC [48, 49]. Monitoring of trough CsA levels is essential to prevent adverse events; trough CsA concentrations that occur during low-dose treatment are approximately $100-250 \mathrm{ng} / \mathrm{ml}$, whereas for high-dose CsA they are approximately $250-400 \mathrm{ng} / \mathrm{ml}$. The total duration of CsA therapy should not exceed 4-6 months, and treatment with another remission maintenance drug should be initiated. CsA dosages should be adjusted downward, whenever the baseline serum creatinine increases by $>30 \%$, while concomitant use of other nephrotoxic agents should be avoided, and patients with preexisting renal dysfunction probably should not be treated with CsA [43].

Tacrolimus, another calcineurin inhibitor with immunosuppressive properties similar to those of CsA has been considered as an alternative to CsA in IBD treatment. In a small number of trials, administration of 0.1$0.2 \mathrm{mg} / \mathrm{kg}$ of oral tacrolimus in order to achieve blood levels between 5 and $15 \mathrm{ng} / \mathrm{ml}$ in patients with refractory IBD demonstrated average efficacy, suggesting that it may be used as bridging therapy. However, tacrolimus has also exhibited nephrotoxic effects similar to CsA [50, 51].

\section{TNF $\alpha$ Inhibitors}

TNF $\alpha$ is a proinflammatory cytokine that plays an important role in the intestinal inflammation of IBD patients. Thus, its inhibitors, particularly infliximab (a chimeric anti-TNF IgG1 monoclonal antibody) and adalimubab (a recombinant anti-TNF IgG1 monoclonal antibody), and, to a lesser extent, etanercept (a recombinant dimer of human TNF receptor proteins fused and bound to human IgG1 that acts competitively to inhibit the binding of TNF to its cell surface receptor) were evaluated in the treatment of $\mathrm{CD}$. However, recent studies showed increased levels of TNF $\alpha$ in serum and stool of patients with UC, findings that led to clinical trials of $\mathrm{TNF} \alpha$ inhibitor administration to patients with active UC [52]. Although TNF $\alpha$ inhibitors showed great effi- cacy in inducing and maintaining clinical remission in IBD - infliximab and adalimubab in particular, but not etanercept - they are not without serious adverse effects $[53,54]$.

TNF $\alpha$ inhibitor efficacy in several autoimmune diseases, such as rheumatoid arthritis, ankylosing spondylitis, psoriatic arthritis, juvenile idiopathic arthritis, and IBD led to different observations [55]. Although previous reports suggested a possible beneficial role of TNF $\alpha$ inhibitors in the treatment of GN [56-59], more recent reports and greater experience with TNF $\alpha$ inhibitors raised intriguing questions concerning the efficacy of $\mathrm{TNF} \alpha$ inhibitors in $\mathrm{GN}$ as well as demonstrating a possible causative role in the emergence of renal complications such as GN. To our knowledge, GN occurred in at least 19 patients (most of them developing lupus nephritis), during treatment with anti-TNF $\alpha$ [60-68], as indicated in table 2 .

Despite the paucity of data regarding GN in IBD patients as complications of TNF $\alpha$ inhibitor therapy, recent reports supporting a triggering role of $\mathrm{TNF} \alpha$ inhibitors in renal impairment suggest an important adverse effect [69]. A possible mechanism responsible for the development of renal complications during anti-TNF $\alpha$ administration implicates an interaction of anti-TNF $\alpha$ antibodies with TNF $\alpha$ present on glomerular visceral epithelial cells [60]. It has also been proposed that binding of infliximab to TNF $\alpha$ on the lymphocyte plasma membranes might induce apoptosis, releasing immunogenic nucleosomal antigens that promote anti-dsDNA antibody formation [69]. Moreover, the induction of antinuclear antibodies, anti-dsDNA and antineutrophil cytoplasmic antibodies from $\mathrm{TNF} \alpha$ inhibitors may give rise to either lupus-like immune complex GN or antineutrophil cytoplasmic antibody-related necrotizing and crescentic GN in susceptible individuals [70]. The temporal relation of new-onset glomerular disease to drug use, the improvement of clinical symptoms and laboratory abnormalities after drug withdrawal and the administration of immunosuppressive therapy in the majority of patients show that renal complications following the administration of TNF $\alpha$ inhibitors were not coincidental.

\section{Other Agents and Nephrotoxicity in IBD}

In addition to the above-mentioned medical treatments, other agents used in IBD therapy, such as corticosteroids, thiopurines (azathioprine and 6-mercaptopurine), methotrexate and mycophenolate mofetil, showed 
Table 2. TNF $\alpha$ inhibitor-associated renal complications

\begin{tabular}{|c|c|c|c|c|}
\hline Underlying disease & TNF $\alpha$ inhibitors & Renal complication & Cases & Authors \\
\hline Rheumatoid arthritis & Adalimubab & Glomerulonephritis & 1 & Den Broeder et al. [61] \\
\hline Rheumatoid arthritis & Infliximab & Glomerulonephritis & 2 & Chin et al. [62], Stokes et al. [63] \\
\hline Rheumatoid arthritis & Etanercept & Glomerulonephritis & 4 & Kemp et al. [64], Stokes et al. [63] \\
\hline Rheumatoid arthritis & Adalimubab & Lupus nephritis & 1 & Stokes et al. [63] \\
\hline Juvenile idiopathic arthritis & Etanercept & Lupus nephritis & 2 & Stokes et al. [63], Mor et al. [65] \\
\hline Psoriatic arthritis & Etanercept & Glomerulonephritis & 1 & Doulton et al. [66] \\
\hline Psoriatic arthritis & Etanercept & Lupus nephritis & 1 & Haake et al. [67] \\
\hline Rheumatoid arthritis or ankylosing spondylitis & Undefined & Glomerulonephritis & 2 & Saint Marcoux et al. [68] \\
\hline $\begin{array}{l}\text { Rheumatoid arthritis or Crohn's disease or } \\
\text { ankylosing spondylitis or psoriatic arthritis } \\
\text { or juvenile idiopathic arthritis }\end{array}$ & $\begin{array}{l}\text { Etanercept or } \\
\text { infliximab or } \\
\text { adalimubab }\end{array}$ & Lupus nephritis & 5 & Ramos-Casals et al. [69] \\
\hline
\end{tabular}

Review of the literature identified 19 cases with severe renal parenchymal complications during therapy with TNF $\alpha$ inhibitors.

no direct significant effects on renal function. Methotrexate, in particular, although showing potential nephrotoxicity when administered in high doses, exhibited no nephrotoxic effect in conventional doses used in IBD [71]. Regarding azathioprine, no evidence of a direct renal effect has been identified. However, prolonged azathioprine treatment in IBD patients may provoke renal impairment due to development of the hemophagocytic syndrome. The hemophagocytic syndrome, which is caused by excessive activation and proliferation of nonmalignant macrophages, may be triggered by cytomegalovirus, parvovirus or herpes simplex virus infection in immunosuppressed patients such as IBD patients receiving azathioprine. The hemophagocytic syndrome may be accompanied by collapsing glomerulopathy, acute kidney injury and severe nephrotic syndrome [72-74]. Finally, extensive administration of antibiotics such as ciprofloxacin and metronidazole as well as utilization of total parenteral or enteral nutrition do not appear to cause renal impairment although a few case reports have suggested ciprofloxacin-related nephrotoxic effects [75].

\section{Conclusions}

Among 'older' and 'novel' agents utilized in the management of IBD, chiefly ASAs, CsA and biologic agents are potentially nephrotoxic drugs. Since bowel inflammation usually overshadows renal signs and symptoms, it may be difficult to identify the exact cause of renal function deterioration. There is a thin line between renal dysfunction as an extraintestinal manifestation and renal

injury due to medical treatment which cannot always be drawn. Furthermore, the steadily increasing utilization of TNF $\alpha$ inhibitors in IBD demands higher degree of vigilance. Although most experience concerning TNF $\alpha$ inhibitor nephrotoxicity has been gathered from other autoimmune diseases, their potential role in renal damage of IBD patients cannot be ignored. Nevertheless, watchfulness and monitoring of renal function can lead us to early diagnosis, whereas prompt discontinuation of toxic medical treatment is essential to prevent further damage and in many cases fully reverse renal injury.

\section{Disclosure Statement}

The authors have no conflicts of interest to declare.

\section{References}

Nephron Clin Pract 2011;119:c89-c96
1 Loftus EV Jr: Clinical epidemiology of inflammatory bowel disease: incidence, prevalence, and environmental influences. Gastroenterology 2004;126:1504-1517.

2 Oikonomou K, Kapsoritakis A, Eleftheriadis T, Stefanidis I, Potamianos S: Renal manifestations and complications of inflammatory bowel disease. Inflamm Bowel Dis 2010 Sep 14. [Epub ahead of print] DOI: 10.1002/ ibd. 21468 .

>3 Gisbert JP, González-Lama Y, Maté J: 5-Aminosalicylates and renal function in inflammatory bowel disease: a systematic review. Inflamm Bowel Dis 2007;13:629-638.

-4 Pardi DS, Tremaine WJ, Sandborn WJ, McCarthy JT: Renal and urologic complications of inflammatory bowel disease. Am J Gastroenterol 1998;93:504-514. 
5 Engel MA, Neurath MF: New pathophysiological insights and modern treatment of IBD. J Gastroenterol 2010;45:571-583.

6 Carter MJ, Lobo AJ, Travis SP; IBD Section, British Society of Gastroenterology: Guidelines for the management of inflammatory bowel disease in adults. Gut 2004;53(suppl 5):V1-V16.

7 Reenaers C, Louis E, Belaiche J: Current directions of biologic therapies in inflammatory bowel disease. Therap Adv Gastroenterol 2010;3:99-106.

-8 de Jong DJ, Tielen J, Habraken CM, Wetzels JF, Naber AH: 5-Aminosalicylates and effects on renal function in patients with Crohn's disease. Inflamm Bowel Dis 2005; 11:972-976.

-9 World MJ, Stevens PE, Ashton MA, Rainford DJ: Mesalazine-associated interstitial nephritis. Nephrol Dial Transplant 1996;11: 614-621.

10 Rhodes J, Coles GA: An alternative view of 5-ASA formulations. Gut 1995;36:639-640.

-11 Marteau P, Nelet F, Le Lu M, Devaux C: Adverse events in patients treated with 5-aminosalicylic acid: 1993-1994 pharmacovigilance report for Pentasa in France. Aliment Pharmacol Ther 1996;10:949-956.

12 Barbour VM, Williams PF: Nephrotic syndrome associated with sulphasalazine. BMJ 1990;6:818.

13 Thuluvath PJ, Ninkovic M, Calam J, Anderson M: Mesalazine induced interstitial nephritis. Gut 1994;35:1493-1496.

14 Wilcox GM, Reynolds JR, Galvanek EG: Nephrotoxicity associated with olsalazine. Am J Med 1996;100:238-240.

15 Dwarakanath AD, Michael J, Allan RN: Sulphasalazine induced renal failure. Gut 1992; 33:1006-1007.

16 Masson EA, Rhodes JM: Mesalazine associated nephrogenic diabetes insipidus presenting as weight loss. Gut 1992;33:563-564.

- 17 Uslu N, Demir H, Saltik-Temizel IN, Topaloğlu R, Gürakan F, Yüce A: Acute tubular injury associated with mesalazine therapy in an adolescent girl with inflammatory bowel disease. Dig Dis Sci 2007;52: 2926-2929.

18 De Broe ME, Stolear JC, Nouwen EJ, Elseviers MM: 5-Aminosalicylic acid (5-ASA) and chronic tubulointerstitial nephritis in patients with chronic inflammatory bowel disease: is there a link? Nephrol Dial Transplant 1997;12:1839-1841.

19 Popoola J, Muller AF, Pollock L, O’Donnell P, Carmichael P, Stevens P: Late onset interstitial nephritis associated with mesalazine treatment. BMJ 1998;19:795-797.

20 Ransford RA, Langman MJ: Sulphasalazine and mesalazine: serious adverse reactions reevaluated on the basis of suspected adverse reaction reports to the Committee on Safety of Medicines. Gut 2002;51:536-539.
21 Corrigan G, Stevens PE: Review article: interstitial nephritis associated with the use of mesalazine in inflammatory bowel disease. Aliment Pharmacol Ther 2000;14:1-6.

22 Tadic M, Grgurevic I, Scukanec-Spoljar M, Bozic B, Marusic S, Horvatic I, Galesic K: Acute interstitial nephritis due to mesalazine. Nephrology (Carlton) 2005;10:103105.

23 Stretch GL, Campbell BJ, Dwarakanath AD, Yaqoob M, Stevenson A, Morris AI, Rhodes JM: 5-Amino salicylic acid absorption and metabolism in ulcerative colitis patients receiving maintenance sulphasalazine, olsalazine or mesalazine. Aliment Pharmacol Ther 1996;10:941-947.

24 Patel H, Barr A, Jeejeebhoy KN: Renal effects of long-term treatment with 5-aminosalicylic acid. Can J Gastroenterol 2009;23:170176.

25 Van Staa TP, Travis S, Leufkens HG, Logan RF: 5-Aminosalicylic acids and the risk of renal disease: a large British epidemiologic study. Gastroenterology 2004;126:17331739.

-26 Fraser JS, Muller AF, Smith DJ, Newman DJ, Lamb EJ: Renal tubular injury is present in acute inflammatory bowel disease prior to the introduction of drug therapy. Aliment Pharmacol Ther 2001;15:1131-1137.

-27 Mahmud N, O’Toole D, O’Hare N, Freyne PJ, Weir DG, Kelleher D: Evaluation of renal function following treatment with 5-aminosalicylic acid derivatives in patients with ulcerative colitis. Aliment Pharmacol Ther 2002;16:207-215.

28 Poulou AC, Goumas KE, Dandakis DC, Tyrmpas I, Panagiotaki M, Georgouli A, Soutos DC, Archimandritis A: Microproteinuria in patients with inflammatory bowel disease: is it associated with the disease activity or the treatment with 5-aminosalicylic acid? World J Gastroenterol 2006;7;12:739746.

29 Marcus SB, Brown JB, Melin-Aldana H, Strople JA: Tubulointerstitial nephritis: an extraintestinal manifestation of Crohn disease in children. J Pediatr Gastroenterol Nutr 2008;46:338-341.

30 Izzedine H, Simon J, Piette AM, Lucsko M, Baumelou A, Charitanski D, Kernaonet E, Baglin AC, Deray G, Beaufils H: Primary chronic interstitial nephritis in Crohn's disease. Gastroenterology 2002;123:1436-1440.

- 31 Kreisel W, Wolf LM, Grotz W, Grieshaber M: Renal tubular damage: an extraintestinal manifestation of chronic inflammatory bowel disease. Eur J Gastroenterol Hepatol 1996;8:461-468.

- 32 Herrlinger KR, Noftz MK, Fellermann K, Schmidt K, Steinhoff J, Stange EF: Minimal renal dysfunction in inflammatory bowel disease is related to disease activity but not to 5-ASA use. Aliment Pharmacol Ther 2001; 15:363-369.
33 Sandborn WJ: A critical review of cyclosporine therapy in inflammatory bowel disease. Inflamm Bowel Dis 1995;1:48-63.

34 Sandborn WJ: Cyclosporine therapy for inflammatory bowel disease: definitive answers and remaining questions. Gastroenterology 1995;109:1001-1003.

35 Lichtiger S, Present DH, Kornbluth A, Gelernt I, Bauer J, Galler G, Michelassi F, Hanauer S: Cyclosporine in severe ulcerative colitis refractory to steroid therapy. N Engl J Med 1994;30:1841-1845.

36 Sands BE: Immunosuppressive drugs in ulcerative colitis: twisting facts to suit theories? Gut 2006;55:437-441.

37 Meijssen MA: Cyclosporine and inflammatory bowel disease: buying time. Mediators Inflamm 1998;7:145-147.

38 McDonald JW, Feagan BG, Jewell D, Brynskov J, Stange EF, Macdonald JK: Cyclosporine for induction of remission in Crohn's disease. Cochrane Database Syst Rev 2005; 18:CD000297.

-39 Stange EF, Modigliani R, Peña AS, Wood AJ, Feutren G, Smith PR: European trial of cyclosporine in chronic active Crohn's disease: a 12-month study. The European Study Group. Gastroenterology 1995;109:774-782.

40 Fellermann K, Lühmann D, Stange EF: Is there still a role for cyclosporine in the treatment of inflammatory bowel disease? Con argument. Inflamm Bowel Dis 2003;9:198201; discussion 202-204.

- 41 Feagan BG, McDonald JW, Rochon J, Laupacis A, Fedorak RN, Kinnear D, Saibil F, Groll A, Archambault A, Gillies R, et al: Low-dose cyclosporine for the treatment of Crohn's disease. The Canadian Crohn's Relapse Prevention Trial Investigators. N Engl J Med 1994;330:1846-1851.

42 Brynskov J, Freund L, Rasmussen SN, Lauritsen K, de Muckadell OS, Williams N, MacDonald AS, Tanton R, Molina F, Campanini $\mathrm{MC}$, et al: A placebo-controlled, doubleblind, randomized trial of cyclosporine therapy in active chronic Crohn's disease. N Engl J Med 1989;28:845-850.

43 Sandborn WJ, Tremaine WJ, Lawson GM: Clinical response does not correlate with intestinal or blood cyclosporine concentrations in patients with Crohn's disease treated with high-dose oral cyclosporine. Am J Gastroenterol 1996;91:37-43.

44 Bennett WM: Mechanisms of acute and chronic nephrotoxicity from immunosuppressive drugs. Ren Fail 1996;18:453-460.

45 Bennett WM, DeMattos A, Meyer MM, Andoh T, Barry JM: Chronic cyclosporine nephropathy: the Achilles' heel of immunosuppressive therapy. Kidney Int 1996;50:10891100

46 Bennett WM: The nephrotoxicity of immunosuppressive drugs. Nephrol Dial Transplant 1996;11:1899-1901 
47 Shang MH, Yuan WJ, Zhang SJ, Fan Y, Zhang $Z$ : Intrarenal activation of renin angiotensin system in the development of cyclosporine A induced chronic nephrotoxicity. Chin Med J (Engl) 2008;5:983-988.

48 Sandborn WJ: Cyclosporine therapy for inflammatory bowel disease: definitive answers and remaining questions. Gastroenterology 1995;109:1001-1003.

- 49 Fellermann K, Lühmann D, Stange EF: Is there still a role for cyclosporine in the treatment of inflammatory bowel disease? Con argument. Inflamm Bowel Dis 2003;9:198201; discussion 202-204.

-50 Baumgart DC, Pintoffl JP, Sturm A, Wiedenmann B, Dignass AU: Tacrolimus is safe and effective in patients with severe steroid-refractory or steroid-dependent inflammatory bowel disease - a long-term follow-up. Am J Gastroenterol 2006;101:1048-1056.

- 51 Yamamoto S, Nakase H, Mikami S, Inoue S, Yoshino T, Takeda Y, Kasahara K, Ueno S, Uza N, Kitamura H, Tamaki H, Matsuura M, Inui K, Chiba T: Long-term effect of tacrolimus therapy in patients with refractory ulcerative colitis. Aliment Pharmacol Ther 2008;1:589-597.

-52 Blonski W, Lichtenstein GR: Safety of biologic therapy. Inflamm Bowel Dis 2007;13: 769-796.

53 Nash PT, Florin TH: Tumour necrosis factor inhibitors. Med J Aust 2005;15:205-208.

-54 Oikonomou KA, Kapsoritakis AN, Tsiopoulos FD, Tsikouras AN, Potamianos S: Emergence of Crohn's disease in juvenile idiopathic arthritis during treatment with etanercept: a causal link or a mere coincidence? J Gastrointestin Liver Dis 2010;19:342.

55 Haraoui B, Krelenbaum M: Emergence of Crohn's disease during treatment with the anti-tumor necrosis factor agent etanercept for ankylosing spondylitis: possible mechanisms of action. Semin Arthritis Rheum 2009:39:176-181.

-56 Thonhofer R, Soleiman A, Kriessmayr M, Thonhofer U, Wipfler E, Gaugg M, Eder S, Erlacher L: Decrease of proteinuria in a patient with adult-onset Still's disease and glomerulonephritis after anti-TNF $\alpha$ therapy. Scand J Rheumatol 2006;35:485-488.
57 Verschueren P, Lensen F, Lerut E, Claes K, De Vos R, Van Damme B, Westhovens R: Benefit of anti-TNF $\alpha$ treatment for nephrotic syndrome in a patient with juvenile inflammatory bowel disease associated spondyloarthropathy complicated with amyloidosis and glomerulonephritis. Ann Rheum Dis 2003; 62:368-369.

58 Little MA, Bhangal G, Smyth CL, Nakada MT, Cook HT, Nourshargh S, Pusey CD: Therapeutic effect of anti-TNF- $\alpha$ antibodies in an experimental model of anti-neutrophil cytoplasm antibody-associated systemic vasculitis. J Am Soc Nephrol 2006;17:160169.

59 Sakellariou GT, Vounotrypidis P, Berberidis $\mathrm{C}$ : Infliximab treatment in two patients with psoriatic arthritis and secondary IgA nephropathy. Clin Rheumatol 2007;26:11321133.

60 den Broeder AA, Assmann KJ, van Riel PL, Wetzels JF: Nephrotic syndrome as a complication of anti-TNF $\alpha$ in a patient with rheumatoid arthritis. Neth J Med 2003;61:137141.

61 Chin G, Luxton G, Harvey J: Infliximab and nephritic syndrome. Nephrol Dial Transplant 2005;20:2824-2826.

62 Stokes MB, Foster K, Markowitz GS, Ebrahimi F, Hines W, Kaufman D, Moore B, Wolde D, D’Agati VD: Development of glomerulonephritis during anti-TNF-therapy for rheumatoid arthritis. Nephrol Dial Trans plant 2005;20:1400-1406

63 Kemp E, Nielsen H, Petersen LJ, Gam AN, Dahlager J, Horn T, Larsen S, Olsen S: Newer immunomodulating drugs in rheumatoid arthritis may precipitate glomerulonephritis. Clin Nephrol 2001;55:87-88.

64 Mor A, Bingham C 3rd, Barisoni L, Lydon E, Belmont HM: Proliferative lupus nephritis and leukocytoclastic vasculitis during treatment with etanercept. J Rheumatol 2005;32: 740-743.

65 Doulton TW, Tucker B, Reardon J, Velasco $\mathrm{N}$ : Antineutrophil cytoplasmic antibody-associated necrotizing crescentic glomerulonephritis in a patient receiving treatment with etanercept for severe rheumatoid arthritis. Clin Nephrol 2004;62:234-238.
66 Haake H, Köneke J, Amann K, vom Dahl J, Janssen U: Development of systemic lupus erythematosus with focal proliferative lupus nephritis during anti-TNF- $\alpha$ therapy for psoriatic arthritis. Med Klin (Munich) 2007; 15:852-857

67 Saint Marcoux B, De Bandt M: Vasculitides induced by TNF $\alpha$ antagonists: a study in 39 patients in France. CRI (Club Rhumatismes et Inflammation). Joint Bone Spine 2006;73: 710-713.

68 Ramos-Casals M, Brito-Zerón P, Muñoz S, Soria N, Galiana D, Bertolaccini L, Cuadrado MJ, Khamashta MA: Autoimmune diseases induced by TNF-targeted therapies: analysis of 233 cases. Medicine (Baltimore) 2007;86:242-251.

69 Charles PJ, Smeenk RJ, De Jong J, Feldmann M, Maini RN: Assessment of antibodies to double-stranded DNA induced in rheumatoid arthritis patients following treatment with infliximab, a monoclonal antibody to tumor necrosis factor $\alpha$ : findings in openlabel and randomized placebo-controlled trials. Arthritis Rheum 2000;43:2383-2390.

70 Ziolkowska M, Maslinski W: Laboratory changes on anti-tumor necrosis factor treatment in rheumatoid arthritis. Curr Opin Rheumatol 2003;15:267-273.

71 Widemann BC, Adamson PC: Understanding and managing methotrexate nephrotoxicity. Oncologist 2006;11:694-703.

72 Thaunat O, Delahousse M, Fakhouri F, Martinez F, Stephan JL, Noël LH, Karras A: Nephrotic syndrome associated with hemophagocytic syndrome. Kidney Int 2006;69: 1892-1898.

73 Babu TG, Boctor D, Davey A, Bond MC, Jacobson K: Cytomegalovirus-associated hemophagocytic syndrome in a child with Crohn disease receiving azathioprine. J Pediatr Gastroenterol Nutr 2004;39:418-421.

74 Gupta S, Weitzman S: Primary and secondary hemophagocytic lymphohistiocytosis: clinical features, pathogenesis and therapy. Expert Rev Clin Immunol. 2010;6:137-154.

75 Lomaestro BM: Fluoroquinolone-induced renal failure. Drug Saf 2000;22:479-485. 


\section{Editorial Comment}

M. El Nahas, Sheffield

This comprehensive review by Oikonomou and colleagues highlights the renal complications of the treatment of inflammatory bowel disease (IBD). Whilst most nephrologists would be familiar with the risks associated with short- and long-term use of 5-aminosalycylates (5ASAs) containing compounds such as sulphasalazine and mesalazine, they need to become aware of the potential nephrotoxicty of newer therapies such as anti-TNF- $\alpha$ treatment. Also, the authors point to the often encountered difficulties related to determining whether renal dysfunction in patients with IBD is caused by extra-intestinal manifestations of the disease or by complications of the treatment. For instance, interstitial nephritis can be caused by either. A thorough clinical evaluation as well as detailed renal histology may guide clinicians. Unfortunately, there are no official guidelines on renal function monitoring in IBD patients. Patients not receiving treatment should be monitored annually. It would be advisable to monitor renal function at regular intervals (every
3 months) after initiation of 5-ASAs. Monitoring should include urine albumin excretion rate as well as serum creatinine measurement and estimated GFR (eGFR). Caution should be exerted in interpreting these results in patients with IBD. Microalbuminuria has been associated with disease flare-ups, is often transient and regresses during quiescent phases. It may reflect the systemic inflammatory response of the vascular endothelium to the disease. eGFR levels may be confounded in patients with IBD and wasting by sarcopenia and associated decreased serum creatinine levels and falsely raised eGFR. Most eGFR formulations correct poorly for changes in body muscle mass. Overall, close monitoring of renal function in patients with IBD is warranted probably through closer coordination between gastroenterologists and nephrologists. Also, improved education of general physicians caring for these patients relating to monitoring of renal function is warranted. 